\title{
Overexpression of Apolipoprotein All in Transgenic Mice Converts High Density Lipoproteins to Proinflammatory Particles
}

\author{
Lawrence W. Castellani, ${ }^{* \ddagger}$ Mohamad Navab, ${ }^{\star}$ Brian J. Van Lenten, ${ }^{\star}$ Catherine C. Hedrick, ${ }^{*}$ Susan Y. Hama, ${ }^{\star}$ Aimie M. Goto, ${ }^{\star}$ \\ Alan M. Fogelman, ${ }^{\star}$ and Aldons J. Lusis ${ }^{\star} \ddagger \S$ \\ *Department of Medicine, ${ }^{\ddagger}$ Molecular Biology Institute, and ${ }^{\S}$ Department of Microbiology and Molecular Genetics, University of \\ California, Los Angeles, Los Angeles, California 90095
}

\begin{abstract}
Previous studies showed that transgenic mice overexpressing either apolipoprotein AI (apoAI) or apolipoprotein AII (apoAII), the major proteins of HDL, exhibited elevated levels of HDL cholesterol, but, whereas the apoAI-transgenic mice were protected against atherosclerosis, the apoAIItransgenic mice had increased lesion development. We now examine the basis for this striking functional heterogeneity. HDL from apoAI transgenics exhibited an enhanced ability to promote cholesterol efflux from macrophages, but HDL from apoAII transgenics and nontransgenics were not discernibly different in efflux studies. In contrast with HDL from nontransgenics and apoAI transgenics, HDL from the apoAII transgenics were unable to protect against LDL oxidation in a coculture model of the artery wall. Furthermore, HDL taken from apoAII-transgenic mice, but not HDL taken from either the apoAI transgenics or nontransgenic littermate controls, by itself stimulated lipid hydroperoxide formation in artery wall cells and induced monocyte transmigration, indicating that the apoAII-transgenic HDL were in fact proinflammatory. This loss in the ability of the apoAII-transgenic HDL to function as an antioxidant/antiinflammatory agent was associated with a decreased content of paraoxonase, an enzyme that protects against LDL oxidation. Reconstitution of the apoAII transgenic HDL with purified paraoxonase restored both paraoxonase activity and the ability to protect against LDL oxidation. We conclude that overexpression of apoAII converts HDL from an anti- to a proinflammatory particle and that paraoxonase plays a role in this transformation. (J. Clin. Invest. 1997. 100:464-474.) Key words: atherosclerosis • lipid peroxidation • monocytes $\bullet$ chemotaxis $\bullet$ cholesterol
\end{abstract}

\section{Introduction}

Epidemiological studies have demonstrated that plasma levels of HDL are inversely correlated with the risk of atherosclerosis, the major cause of heart disease and stroke $(1,2)$. In vitro studies have suggested two mechanisms by which HDL may

Address correspondence to Lawrence W. Castellani, Department of Medicine, Division of Cardiology Room 47-123 CHS, UCLA School of Medicine, Los Angeles, CA 90095. Phone: 310-825-5778; FAX: 310-794-7345; E-mail: lcastell@medicine.medsch.ucla.edu

Received for publication 28 June 1996 and accepted in revised form 18 April 1997.

J. Clin. Invest.

(C) The American Society for Clinical Investigation, Inc.

0021-9738/97/07/0464/11 \$2.00

Volume 100, Number 2, July 1997, 464-474 protect against the disease. First, HDLs remove excess cholesterol from peripheral tissues and transport it to the liver for excretion in the bile, a process termed "reverse cholesterol transport" (3). Second, HDL may protect against the oxidative modification of LDL. Oxidized forms of LDL appear to trigger various inflammatory processes leading to monocyte recruitment into the artery wall, and the oxidation of LDL promotes its uptake by macrophages, leading to the formation of foam cells, which are the hallmark of early atherosclerosis (47). Despite these observations, it is still not certain whether HDL, in vivo, directly protects against atherosclerosis. This uncertainty comes mostly from studies in which atherosclerotic lesion development does not correlate well with plasma HDL cholesterol levels. For example, certain genetic disorders result in very low HDL cholesterol levels yet do not result in large increases in lesion development (8). Thus, the link between HDL and atherosclerosis appears to be much more complicated than what had been predicted by the early epidemiologic studies. HDLs are functionally as well as structurally heterogeneous $(2,3,9)$, and it is likely that certain subfractions of HDL may be more important in preventing atherosclerosis than others. Changes in a small but biologically important HDL subfraction could inhibit the ability of HDL to protect against lesion formation even though total HDL cholesterol is unaltered or even increased. A particularly striking example of functional heterogeneity has emerged from studies of transgenic mice overexpressing the two major proteins of HDL, apolipoprotein AI (apoAI) ${ }^{1}$ and apolipoprotein AII (apoAII). apoAI transgenics are less prone to developing atherosclerotic lesions while apoAII-transgenic mice exhibit increased susceptibility to lesion formation. We now examine the basis of this striking functional heterogeneity by determining whether the HDL from these two transgenic strains exhibit altered ability to function in reverse cholesterol transport or in the inhibition of LDL oxidation.

\section{Methods}

Tissue preparation and lesion analysis. Methods for the quantitation of atheromatous lesions in the aorta were as reported previously (10). Briefly, animals were killed by cervical dislocation and the heart and proximal aorta were excised and washed in phosphate-buffered saline. The basal portion of the heart and proximal aorta were embedded in OCT compound (Miles, Inc., Elkhart, IN), frozen on dry ice, and then stored at $-70^{\circ} \mathrm{C}$ until sectioning. Serial $10-\mu \mathrm{m}$-thick cryosections from the lower or middle portion of the ventricles to the aortic arch were collected on poly-D-lysine-coated slides. In the region from the appearance to the disappearance of the aortic valves, every other

1. Abbreviations used in this paper: apoAI, apolipoprotein AI; hLDL, human LDL; IMEM, Iscove's Modified Eagle's media; ntg, nontransgenic; PAF-AH, platelet-activating factor acetylhydrolase; PON, paraoxonase; VLDL, very low density lipoproteins; tg, transgenic. 
section was collected. In all other regions, every fifth section was collected. The total number of sections examined for lesions ranged from 75 to 110 per mouse. Sections were stained with oil red $\mathrm{O}$ and hematoxylin and counterstained with fast green, and then examined by light microscopy for the identification of atheromatous lesions. All lesion quantitation was done in a blinded fashion by the same person.

Mice and diets. The control (chow) diet was Purina Chow (Ralston-Purina Co., St. Louis, MO) containing $4 \%$ fat. The atherogenic diet was obtained from Teklad (TD 90221; Teklad Premier Laboratory Diets, Madison, WI) and contained $15.75 \%$ fat, $1.25 \%$ cholesterol, and $0.5 \%$ sodium cholate. apoAII-transgenic mice were derived as described previously (10) and contained $\sim 4.5 \mathrm{~kb}$ of sequence $5^{\prime}$ to the first exon of the mouse apoAII gene and $\sim 8.5 \mathrm{~kb}$ of sequence $3^{\prime}$ to the fourth exon of the mouse apoII gene. apoAI-transgenic mice (11) were generously provided by Dr. Jan Breslow (Rockefeller University, New York). The apoAI-transgenic mice were backcrossed to C57BL/6J mice for over 10 generations in our laboratory so that all transgenic mice were of a common genetic background. Combined apoAI/AII-transgenic mice were produced by crossing the apoAI and AII transgenics and selecting those mice that inherit both transgenes. Nontransgenic littermates were used as controls in all experiments. Therefore, transgenic and nontransgenic mice had similar, but not identical, genetic backgrounds, since linked genes in the transgene region could not be removed by backcrossing for 10 generations. However, the donor strain contribution would be no more than a few percent.

Lipid/lipoprotein assays and isolation of HDL. Mice were fasted for $12 \mathrm{~h}$ before retroorbital bleeding under isoflurane anesthesia, using heparin as the anticoagulant. Plasma HDL cholesterol levels were determined as described previously (10). HDL $(d=1.063-1.21 \mathrm{~g} / \mathrm{ml})$ was isolated by sequential density ultracentrifugation from aliquots of pooled mouse plasmas at $15^{\circ} \mathrm{C}$ in the absence of EDTA to avoid inactivation of paraoxonase. HDL was also isolated by gel filtration chromatography using an FPLC system (Pharmacia LKB Biotechnology, Piscataway, NJ) with two Superose 6 columns connected in series (10). Lipoprotein concentrations are expressed according to their protein content.

Monocyte chemotaxis assay. Cocultures of human aortic endothelial cells and smooth muscle cells, generated as described previously (12), were incubated with freshly isolated human LDL at 350 $\mu \mathrm{g} / \mathrm{ml}$ in the absence or presence of various test compounds for 18-24 h. Monocyte chemotactic activity was measured in supernatants collected from cocultures of human aortic endothelial and smooth muscle cells. The supernatants were collected and added to a standard Neuroprobe chamber (Neuro Probe, Cabin John, MD), with the monocytes added to the top. The monocytes were isolated by a modification of the Recalde procedure (13). The chamber was incubated for $1 \mathrm{~h}$ at $37^{\circ} \mathrm{C}$. After the incubation, the chamber was disassembled and the nonmigrated monocytes were wiped off. The membrane was then air dried and fixed with $1 \%$ glutaraldehyde and stained with $0.1 \%$ Crystal Violet dye. The number of migrated monocytes was determined microscopically and expressed as the mean \pm SEM of 12 fields counted in triplicate wells.

Lipid hydroperoxide, arylesterase/paraoxonase, and platelet-activating factor acetylhydrolase assays. HDL samples were assayed for arylesterase activity using $1.0 \mathrm{mM}$ phenylacetate as substrate (14). The cuvette contained $1.0 \mathrm{mM}$ phenylacetate in $20 \mathrm{mM}$ Tris- $\mathrm{HCl}, \mathrm{pH}$ 8.0. The reaction was initiated by the addition of the lipoprotein sample and the increase in the absorbance at $270 \mathrm{~nm}$ was recorded over a 90 -s period. Blanks were included to correct for the spontaneous hydrolysis of phenylacetate. Enzymatic activity was calculated from the molar extinction coefficient $1,310 \mathrm{M}^{-1} \mathrm{~cm}^{-1}$. A unit of arylesterase activity is defined as $1 \mu \mathrm{mol}$ phenylacetate hydrolyzed per min under the above assay conditions (14). Identical results were obtained using paraoxon as a substrate and determining the absorbance at $405 \mathrm{~nm}$ (14). Platelet-activating factor acetylhydrolase (PAF-AH) activity was determined using 2-[3 $\mathrm{H}$-acetyl] PAF as a substrate (15). The ${ }^{3} \mathrm{H}-$ acetate generated after $s n-2$ hydrolysis was separated from labeled substrate by solid phase extraction chromatography and quantitated by liquid scintillation counting. Lipid hydroperoxide levels were determined as described previously (16).

Cholesterol efflux assays. After $5 \mathrm{~d}$ in culture, human monocyte macrophages were transferred to $10 \%$ lipoprotein-deficient serum (LPDS) for $16 \mathrm{~h}$ to deplete the cells of cholesterol. At the end of this time, cells were cholesterol-loaded by transferring to Iscove's Modified Eagle's media (IMEM) containing 1\% FBS, 5\% LPDS, and 100 $\mu \mathrm{g} / \mathrm{ml}$ radiolabeled $\beta$-migrating VLDL as described previously (17). After $48 \mathrm{~h}$, the cell cholesterol pools were allowed to equilibrate by washing three times with IMEM and incubating $16 \mathrm{~h}$ with $1 \mathrm{mg} / \mathrm{ml}$ HSA in IMEM. The media were then removed from cells, the cells washed three times with IMEM, and then incubated for $24 \mathrm{~h}$ with medium containing either IMEM with $0.1 \%$ BSA alone (negative control) or containing either human LDL, AII transgenic HDL, AI transgenic HDL, or nontransgenic (ntg) HDL at $400 \mu \mathrm{g} / \mathrm{ml}$ protein. After removal of the media and washing the cells three times with PBS, lipids were extracted from cells by adding $1.0 \mathrm{ml}$ of hexane/isopropanol (3:2) for $30 \mathrm{~min}$ at room temperature. Extracts were dried under nitrogen and dissolved in $60 \mu \mathrm{l}$ of isopropanol. Duplicate $20-\mu \mathrm{l}$ aliquots were spotted on TLC plates and developed in hexane/ethyl ether/acetic acid/methanol (85:15:1:1). Samples were run against cholesterol and cholesterol ester standards. The outer lanes containing the standards were soaked in methanol/sulfuric acid (90:10), and then baked at $85^{\circ} \mathrm{C}$ for $10 \mathrm{~min}$ to visualize the lipids. To determine the distribution of radiolabel among free and esterified cholesterol, the regions corresponding to the stained standards were scraped and counted by liquid scintillation counting.

Supplementation of HDL with paraoxonase. HDL isolated by density ultracentrifugation were preincubated with purified human paraoxonase $(5 \mu \mathrm{g} / \mathrm{ml})$ (kindly provided by Dr. Bert La Du, University of Michigan, Ann Arbor, MI). After preincubation at $37^{\circ} \mathrm{C}$ for $4 \mathrm{~h}$, the unbound paraoxonase was removed by filtering through a $100-\mathrm{kD}$ molecular weight cutoff filter (Amicon, Beverly, MA). The activity of paraoxonase associated with the HDL was determined as described above, both before and after supplementation with paraoxonase. The HDL were then used in coculture assays as described above.

Polyacrylamide gel electrophoresis. Aliquots of ultracentrifugally isolated HDL containing equal amounts of protein $(0.5 \mu \mathrm{g})$ were run under reducing, denaturing conditions on 4-20\% Tris/glycine polyacrylamide gels (Novex, San Diego, CA). Molecular weight markers (Novex Mark 12 wide-range protein standards; Novex,) were run in the outer lanes. After separation, protein bands were visualized by silver staining (Novex Silver Express silver staining kit; Novex).

\section{Results}

A previous study showed that mice overexpressing human apoAI exhibited increased HDL cholesterol levels and increased resistance to diet-induced atherosclerosis on a high fat atherogenic diet (18). We have independently confirmed these results (Table I and Fig. 1). Overexpression of mouse apoAII also resulted in increased HDL-cholesterol levels, but in contrast with the results with apoAI, the apoAII-transgenic mice showed enhanced susceptibility to diet-induced atherosclerosis and actually developed significant fatty streak lesions on a low fat chow diet (Table I and Fig. 1). These lesion and lipid data for the apoAII transgenics have been reported previously (10) and are included in Table I and Fig. 1 to facilitate comparison with the apoAI transgenics. apoAII-transgenic mice also developed more lesions than nontransgenic littermates on a high fat atherogenic diet; however, the stimulatory effect of apoAII on lesion development was much more pronounced on the chow diet, as we reported previously (10). We did not observe any qualitative differences in lesions between the apoAII- and 
Table I. Composition of HDL in Nontransgenic (Ntg), ApoAI-transgenic (AItg), and ApoAII-transgenic (AIItg) Mice

\begin{tabular}{lccc}
\hline & Ntg & AItg & AIItg \\
\hline $\begin{array}{l}\text { HDL-cholesterol } \\
\text { levels (mg/dl) }\end{array}$ & $53 \pm 2(17)$ & $124 \pm 4(15)^{*}$ & $128 \pm 2(17)^{*}$ \\
$\begin{array}{l}\text { apoAII levels (mg/dl) } \\
\text { apoAI levels (mg/dl) } \\
\text { mouse }\end{array}$ & $21 \pm 3(12)$ & $26 \pm 4(14)$ & $60 \pm 5(12)^{* \ddagger}$ \\
$\begin{array}{l}\text { apoAII/AI ratio } \\
\text { (mass/mass) }\end{array}$ & $126 \pm 4(12)$ & $325 \pm 12(9)^{*}$ & $108 \pm 6(13)^{\ddagger}$ \\
& 0.17 & $0.08^{*}$ & $0.56^{* \ddagger}$ \\
\hline
\end{tabular}

The apoAI-transgenic mice were derived by transferring a human apoAI transgene (reported in reference 11) onto the background of strain C57BL/6J. The mice were then backcrossed to strain C57BL/6J for 10 or more generations in our laboratory. Plasma lipid and apolipoprotein levels were determined using enzymatic or immunological assays as previously described (10). Human apoAI was distinguished from mouse apoAI by specific antibodies; however, the apoAI levels reported in the table include both human and mouse apoAI. Results from male and female mice are combined, although sexes differed somewhat in all four parameters examined. Values are given as mean \pm SEM. The following symbols indicate significance $(P<0.05)$ between the means of the various groups as calculated by $t$ test. *Significantly different from the Ntg group. ${ }^{\ddagger}$ Significantly different than the AItg group.

apoAI-transgenic strains. We have shown hematoxylin and eosin sections and oil red $\mathrm{O}$-stained sections of lesions in the apoAII-transgenic mice in a previous report (19). Expression of human rather than mouse apoAII also resulted in increased
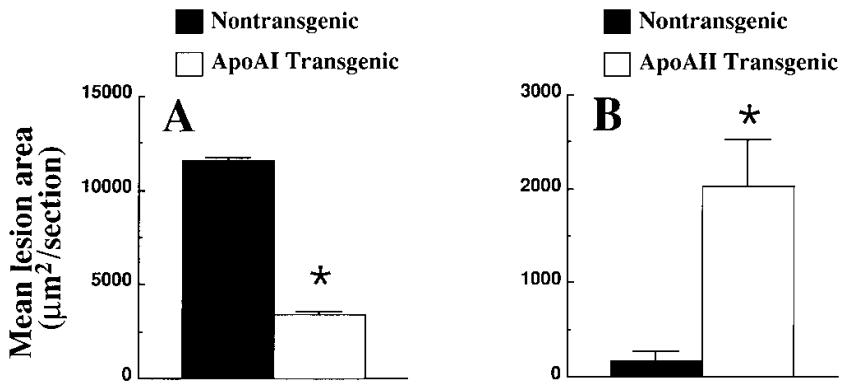

Figure 1. Fatty streak lesions in the proximal aorta of apoAI- and apoAII-transgenic mice and their nontransgenic littermates. Aortic lesion size was determined by quantitation of the lipid-staining area in sections from the proximal aorta (10). Combined data from male and female mice are reported for the transgenics and their nontransgenic littermates. The nontransgenic mice used in these studies do not develop lesions on a chow diet, but are susceptible to lesion development on an atherogenic diet. $(A)$ Lesion data for apoAI-transgenic $(n=10)$ and nontransgenic $(n=11)$ mice are reported after $15 \mathrm{wk}$ on the atherogenic diet, since the protective effect of apoAI could not be demonstrated under conditions in which the nontransgenic mice don't develop lesions. $(B)$ Lesion data for apoAII-transgenic $(n=10)$ and nontransgenic $(n=12)$ mice are reported for animals maintained on a normal chow diet, since the stimulatory effect of apoAII on lesion development was more pronounced under conditions where the nontransgenic animals don't develop lesions. Results on lesions in the apoAII-transgenic mice were as previously reported (10). All lesion data are given as mean \pm SEM expressed in micrometers per section squared. The following symbols indicate significance $(P<0.05)$ between the means of the various groups as calculated by $t$ test. *Significantly different from nontransgenic controls. susceptibility to atherosclerosis (20). The plasma levels and compositions of HDL from the ntg mice, apoAI-transgenic (AItg), and apoAII-transgenic (AIItg) mice used in our studies are shown in Table I. Fig. 2 shows an electrophoretic separation of proteins present in HDL isolated from nontransgenic C57BL/6J and apoAI- and apoAII-transgenic mice by ultracentrifugation. A number of quantitative differences were apparent, although results varied somewhat between preparations, presumably reflecting different levels of contamination. Using immunoblotting, we previously showed that apoE levels were markedly reduced in HDL from apoAII-transgenic mice as compared with nontransgenic littermates (10). apoAIItransgenic mice also have significantly larger HDL particles than nontransgenic or apoAI-transgenic mice (10). Both the apoAI and apoAII transgenes were bred onto a genetic background of inbred strain C57BL/6J by backcrossing for 10 or more generations. In all experiments described, nontransgenic littermates were used as controls. Since the apoAII-transgenic mice showed the greatest contrast in atherosclerosis on the chow diet, the subsequent studies were performed with chowfed mice.

To test whether the HDL from the transgenic mice differed in the ability to promote cellular cholesterol efflux, macrophages were loaded with labeled cholesterol (17) for $48 \mathrm{~h}$, and then incubated for $24 \mathrm{~h}$ with HDL isolated from mouse plasma by ultracentrifugation. Albumin and LDL controls did not significantly affect cholesterol efflux, whereas the cellular content

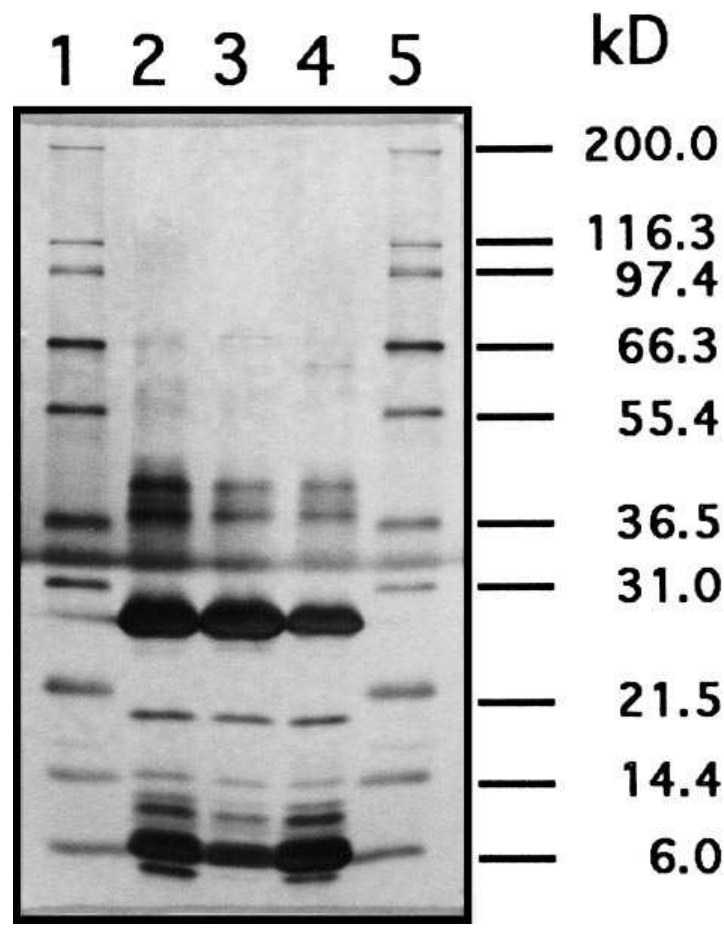

Figure 2. Separation of HDL apolipoproteins by polyacrylamide gel electrophoresis. Aliquots of ultracentrifugally isolated HDL containing equal amounts of protein $(0.5 \mu \mathrm{g})$ were run under reducing, denaturing conditions on $4-20 \%$ Tris/glycine polyacrylamide gels. Molecular weight markers were run in lanes 1 and 5 . After separation, protein bands were visualized by silver staining. Lanes 1 and 5, molecular weight markers; lane 2, nontransgenic HDL; lane 3, apoAI transgenic HDL; lane 4, apoAII transgenic HDL. 


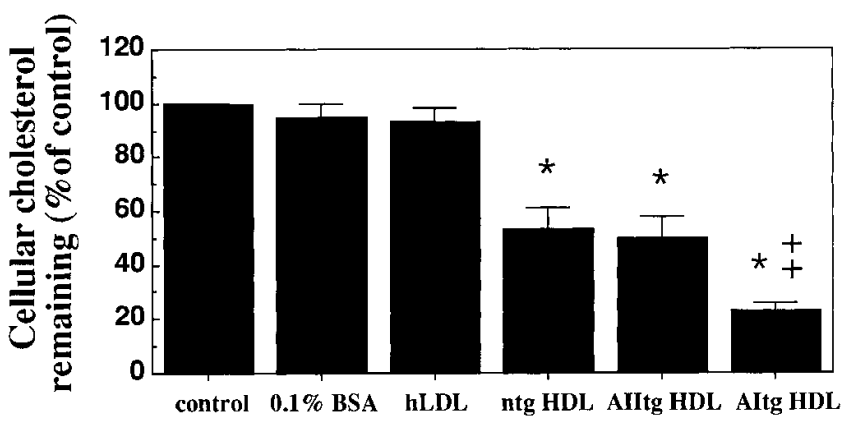

Figure 3. Effect of transgenic and nontransgenic HDL on cholesterol efflux from cholesterol-loaded human macrophages. Pooled plasma samples were obtained from apoAII-transgenic mice $(n=18)$, which overexpress murine apoAII, nontransgenic littermates $(n=22)$, and apoAI-transgenic mice $(n=12)$, which express human apoAI. All mice were maintained on a standard laboratory chow diet and fasted overnight. HDL $(d=1.063-1.21 \mathrm{~g} / \mathrm{ml})$ was isolated by sequential density ultracentrifugation as described previously (10). Cholesterol efflux was then determined using human monocyte macrophages that were preloaded with radioactive cholesterol for $48 \mathrm{~h}$ (17). Data are expressed as percent radioactivity remaining in the macrophages after $24 \mathrm{~h}$ incubation with either dilapidated bovine serum albumin $(0.1 \% B S A)$, human LDL $(h L D L)(2.0 \mathrm{mg} / \mathrm{ml}), 400 \mu \mathrm{g} / \mathrm{ml}$ nontransgenic HDL (ntg HDL), apoAII-transgenic HDL (AIItg HDL), or apoAI transgenic HDL (AItg $H D L)$. All values are given as mean \pm SEM for four separate assays. The following symbols indicate significance $(P<0.05)$ between the means of the various groups as calculated by $t$ test. *Significantly different from control. "Significantly different from ntg HDL and AIItg HDL.

of cholesterol was markedly reduced after incubation with HDL (Fig. 3). The AItg HDL exhibited a significantly greater ability to promote cholesterol efflux than either the ntg or AIItg HDL, which were equally effective. Some studies have suggested that certain quantitatively minor HDL subfractions, termed pre-beta HDL, play an important role as the initial acceptors of cellular cholesterol $(3,21)$. These particles are very dense and are not effectively isolated by density ultracentrifugation. To test whether the inability to demonstrate a difference in cholesterol efflux between ultracentrifugally isolated HDL from the ntg and AIItg mice may have been due to the loss of the pre-beta HDL fraction, we repeated the cholesterol efflux studies using plasma from the AIItg-transgenic and ntg mice as described (21), and determined the total cholesterol efflux by pooling and counting all plasma HDL fractions including the pre-beta HDL. No differences in total cholesterol efflux were observed between the ntg and AIItg mice when the data were normalized to either HDL cholesterol (determined as described in the methods section) or total HDL protein (based on the protein concentration of HDL isolated by ultracentrifugation from an aliquot of the plasma) $(1,860 \pm 270$ and $1,670 \pm 310 \mathrm{dpm}$ of radioactive cholesterol for $\mathrm{ntg}$ and apoAII transgenics, respectively; data are expressed as the mean \pm SEM).

Since HDL from AIItg mice did not exhibit a reduced capacity to promote cholesterol efflux from cells, we examined whether they were altered in the ability to inhibit LDL oxidation. We used a coculture model of the artery wall consisting of a monolayer of aortic endothelial cells overlying the extracellular matrix produced by, and on top of, a layer of smooth
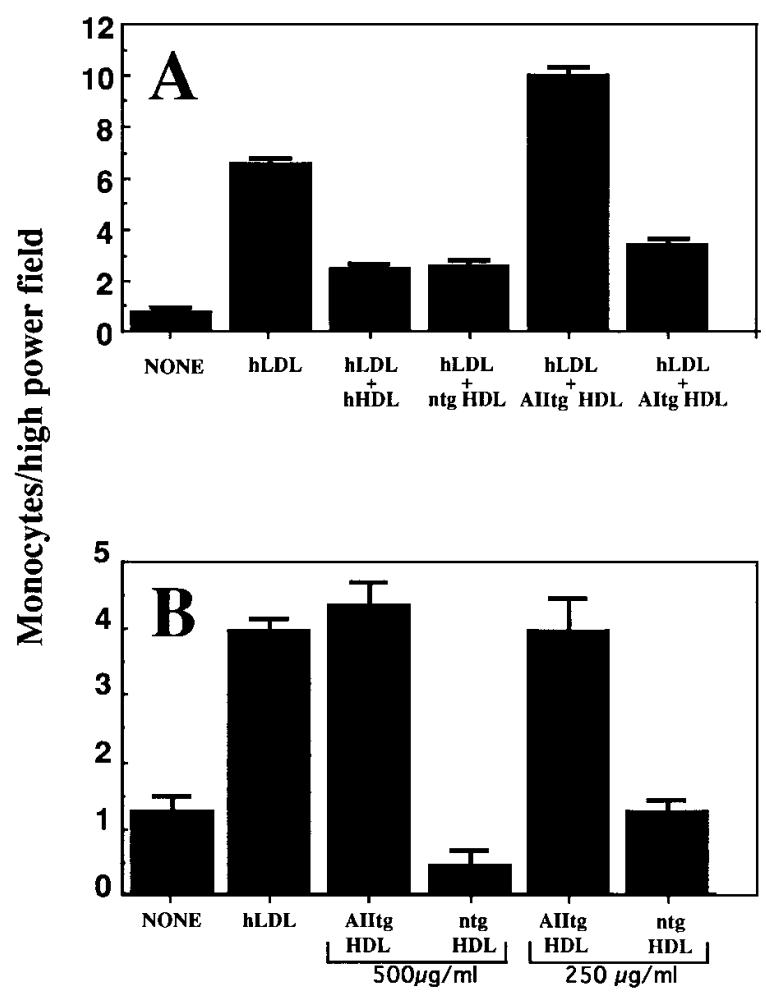

Figure 4. Effect of transgenic and nontransgenic HDL on LDL oxidation and monocyte transmigration in a coculture assay. $(A)$ The ability of HDL to protect LDL from oxidative modification was studied in cocultures of human aortic endothelial and smooth muscle cells. Human and mouse HDL $(d=1.063-1.21 \mathrm{~g} / \mathrm{ml})$ and human LDL $(d=1.019-1.063 \mathrm{~g} / \mathrm{ml})$ were isolated by sequential ultracentrifugation (10) and were used at $500 \mu \mathrm{g}$ HDL and $350 \mu \mathrm{g}$ LDL protein $/ \mathrm{ml}$ of medium. Cocultures of human aortic endothelial and smooth muscle cells were established as described previously $(12,22-24)$. Coculture incubations were carried out for $7 \mathrm{~h}$ with either no lipoproteins added (NONE), human LDL alone ( $h L D L)$, human LDL and human HDL $(h L D L+h H D L)$, human LDL and nontransgenic HDL ( $h L D L+n t g H D L)$, human LDL and apoAII-transgenic HDL $(h L D L+$ AIItg $H D L)$, and human LDL and apoAI-transgenic HDL $(h L D L+A I t g H D L)$. After incubation for $7 \mathrm{~h}$, the culture media from four wells were pooled and loaded into individual wells in a standard neuroprobe chemotaxis chamber. A porous membrane was then placed over the wells and medium containing human monocytes was added to wells on the opposite side of the membrane. After $3 \mathrm{~h}$, the membranes were removed and the number of monocytes that had migrated through the membrane were counted. Monocyte transmigration is expressed as monocytes per high powered field. Values are given as mean \pm SEM for data from four chemotaxis wells. We have observed a complete agreement between the values for monocyte migration through the endothelial cells in the coculture and monocyte migration through the filters. $(B)$ The effect of HDL alone on monocyte transmigration, without added LDL, was examined in the coculture assay. Coculture incubations were carried out as described in $A$, with the following additions to each incubation: no additions (NONE), human LDL alone $(350 \mu \mathrm{g} / \mathrm{ml})$, nontransgenic HDL alone in two concentrations (500 and $250 \mu \mathrm{g} / \mathrm{ml}$ ), or apoAII-transgenic HDL alone in two concentrations (500 and $250 \mu \mathrm{g} / \mathrm{ml}$ ). Monocyte transmigration is expressed as monocytes per high powered field.

muscle cells. Such a multilayer coculture provides a microenvironment in which exogenously added LDL becomes oxidatively modified in the subendothelial matrix. This oxidized LDL induces the synthesis of monocyte chemotactic protein-1 


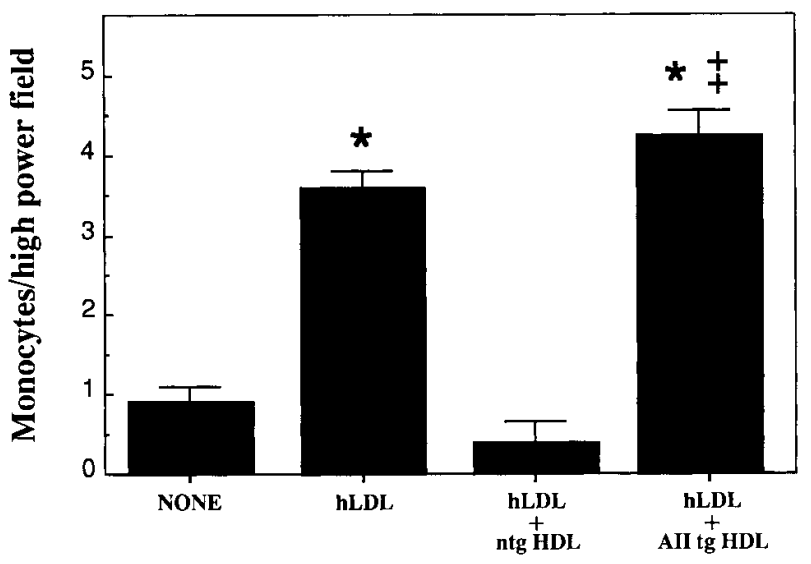

Figure 5. Effect of apoAII-transgenic and nontransgenic HDL isolated by gel filtration on LDL oxidation and monocyte transmigration in a coculture assay. The ability of HDL to protect LDL from oxidative modification was studied in cocultures of human aortic endothelial and smooth muscle cells. Mouse HDL were isolated by gel filtration using two Superose 6 columns connected in series as described previously (10) and were used at $500 \mu \mathrm{g}$ HDL and $350 \mu \mathrm{g} \mathrm{hu}-$ man LDL protein $/ \mathrm{ml}$ of medium. Co-cultures of human aortic endothelial and smooth muscle cells were established as described previously (12,22-24). Coculture incubations were carried out for $7 \mathrm{~h}$ with either no lipoproteins added (NONE), human LDL alone $(h L D L)$, human LDL and nontransgenic HDL $(h L D L+n t g H D L)$, and human LDL and apoAII-transgenic HDL $(h L D L+$ AIItg HDL). After incubation for $7 \mathrm{~h}$, the culture media from four wells were pooled and loaded into individual wells in a standard neuroprobe chemotaxis chamber. A porous membrane was then placed over the wells and medium containing human monocytes was added to wells on the opposite side of the membrane. After $3 \mathrm{~h}$, the membranes were removed and the number of monocytes that had migrated through the membrane were counted. Monocyte transmigration is expressed as monocytes per high powered field. Values are given as mean \pm SEM for data from four chemotaxis wells. We observed a complete agreement between the values for monocyte migration through the endothelial cells in the coculture and monocyte migration through the filters. All values are given as mean \pm SEM for four separate assays. The following symbols indicate significance $(P<$ 0.05 ) between the means of the various groups as calculated by $t$ test. *Significantly different from experiments with no lipoproteins added $(N O N E) .{ }^{\ddagger}$ Significantly different from hLDL + ntg HDL.

that can then be recovered in the medium and its level assessed by the ability to induce monocyte adhesion and transmigration $(21,22)$. As shown in Fig. $4 A$, monocyte transmigration was stimulated in cocultures preincubated with human LDL and, as previously reported, this stimulation was blocked by the addition of human HDL (12). HDL isolated from the ntg and AItg mice also protected against LDL oxidation. However, HDL isolated from AIItg mice failed to protect and actually increased monocyte transmigration above that seen with LDL alone (Fig. $4 A$ ). These experiments were repeated using six different preparations of lipoproteins and aortic wall cells and using a wide range of concentrations of HDL. In each case, AIItg HDL was strikingly different from the other HDLs in that it lacked the ability to protect LDL from oxidation (data not shown). We also examined the ability of HDL isolated by gel filtration chromatography to protect against LDL oxidation in the coculture (Fig. 5). The results were not signifi- cantly different from those performed with HDL isolated by ultracentrifugation. In work not reported here, we have examined the ability of HDL isolated from apoAI- and apoAIItransgenic and nontransgenic mice that had been maintained on the atherogenic diet for $8 \mathrm{wk}$ to protect against LDL oxidation in our coculture experiments. We observed that the absolute degree of protection afforded by the HDL from all three strains was reduced on the atherogenic diet compared with the chow diet, but the relative degree of protection among the three strains was consistent with the results observed on the chow diet.

Because AIItg HDL + human LDL (hLDL) appeared to increase monocyte transmigration above that observed with hLDL alone (Fig. $4 A$ ), we tested whether AIItg HDL was stimulatory rather than inhibitory with respect to monocyte transmigration and lipid oxidation. As shown in Fig. 4 B, AIItg HDL markedly stimulated monocyte transmigration even in the absence of added LDL. AIItg HDL that had not been incubated in coculture did not stimulate monocyte transmigration (data not shown). To test whether AIItg HDL exhibits prooxidant activity, we measured the ability of various lipoprotein preparations to stimulate lipid peroxidation of LDL. Cells were preincubated with isolated lipoproteins overnight, and then washed and incubated overnight with LDL, and the levels of lipid hydroperoxides in the medium were determined. As shown in Fig. 6, preincubation with ntg and AItg HDL did not stimulate lipid hydroperoxide formation, whereas preincubation with AIItg HDL dramatically stimulated lipid peroxidation of LDL. Lipid hydroperoxide levels on the HDL themselves before incubation in the coculture were low and similar in all groups $(2.67 \pm 0.37,3.21 \pm 0.28$, and $2.93 \pm 0.32$ lipid hydroperoxides $[\mu \mathrm{g} / \mathrm{mg}$ HDL protein], for nontransgenic, and apoAII- and apoAI-transgenic mice, respectively; data are expressed as the mean \pm SEM). Interestingly, HDL isolated from

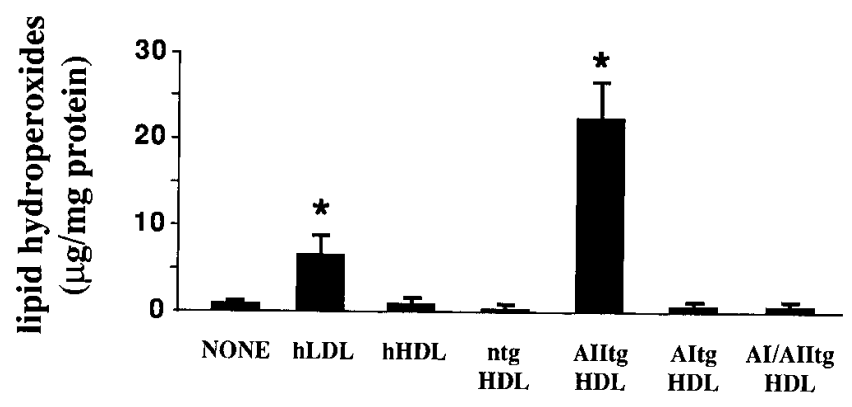

Figure 6. HDL from apoAII-transgenic mice stimulate the oxidation of LDL by vascular cells. Cocultures (as described in Fig. 3 ) were incubated with either no additions (NONE) or with $500 \mu \mathrm{g} / \mathrm{ml}$ of the following lipoprotein preparations: human LDL $(h L D L)$, human HDL ( $h H D L)$, nontransgenic HDL (ntg $H D L$ ), apoAII-transgenic HDL (AIItg $H D L$ ), apoAI-transgenic HDL (AItg $H D L$ ), or apoAI/ apoAII-transgenic HDL (AI/AIItg HDL). After incubation for $24 \mathrm{~h}$, the medium and added lipoproteins were removed. After washing, the cells were incubated overnight with human LDL $(500 \mu \mathrm{g} / \mathrm{ml})$. The levels of lipid peroxides in the medium were then determined (16). The data are expressed as micrograms of linoleate hydroperoxide equivalent per milligram of LDL protein. Values are given as mean \pm SEM for results from three separate experiments. The following symbols indicate significance $(P<0.05)$ between the means of the various groups as calculated by $t$ test. *Significantly different from experiments without preincubation with lipoproteins (NONE). 


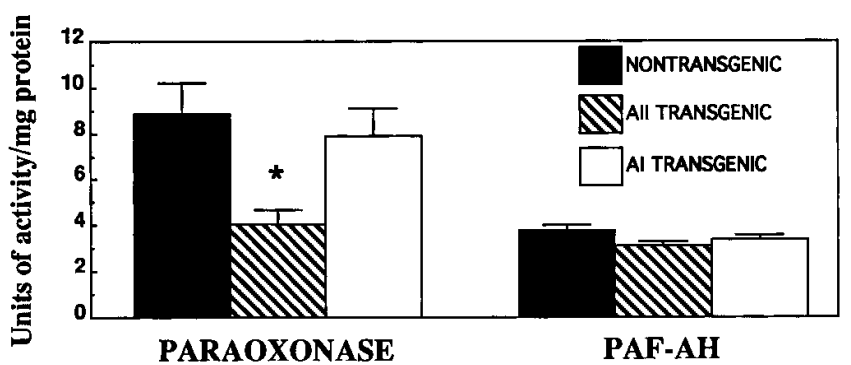

Figure 7. Paraoxonase and PAF-AH activities in HDL from apoAIand apoAII-transgenic mice. Paraoxonase (14) and PAF-AH (15) activities were determined in ultracentrifugally isolated nontransgenic, and apoAII- and apoAI-transgenic HDL. The data are expressed as units of activity (nanomoles substrate hydrolyzed per minute) per milligram HDL protein using phenylacetate and nitrophenol as substrate for the paraoxonase and PAF-AH assays, respectively. Values are given as the mean \pm SEM for results from three separate experiments. The following symbols indicate significance $(P<0.05)$ between the means of the various groups as calculated by $t$ test. *Significantly different from nontransgenics.

transgenic mice expressing both human apoAI and mouse apoAII (AI/AIItg) resembled ntg and AItg HDL in this assay (Fig. 6). This suggests that the functional characteristics of the HDL depend not on the absolute levels of apoAII in plasma but, rather, on the ratio of apoAI to apoAII.

It is likely that the ability of HDL to protect against LDL oxidation is mediated in part by certain enzymes that are capable of destroying biologically active lipids in LDL. Previous studies have revealed two enzymes carried on HDL, paraoxonase (PON), and PAF-AH, that are capable of inhibiting LDL oxidation by $\mathrm{Cu}^{++}$in vitro and in the coculture system (23-30). To test whether the proinflammatory nature of AIItg HDL resulted from altered levels of these enzymes, the activities of both enzymes were determined in total plasma and in isolated HDL preparations. In several separate preparations, paraoxonase activity was decreased by $50 \%$ or more in AIItg HDL as compared with ntg HDL, whereas PAF-AH activity was not significantly changed (Fig. 7). Activities of both enzymes were not significantly different in AItg HDL as compared with ntg HDL (Fig. 7). When HDL were isolated from plasma by gel filtration, paraoxonase eluted entirely with HDL in both ntg and AIItg mice (data not shown). Paraoxonase levels in the HDL fraction were similar between nontransgenic and apoAII-transgenic mice when equal volumes of plasma were applied to the columns. This was in agreement with the observation that total plasma paraoxonase activity between the nontransgenic and apoAII-transgenic mice were similar $(14.7 \pm 2.1$ and $13.1 \pm 2.4 \mathrm{U}$ activity/ml plasma for nontransgenic and apoAII-transgenic mice, respectively; data are expressed as mean \pm SEM). However, as with HDL prepared by ultracentrifugation, paraoxonase in AIItg HDL isolated by gel filtration was $<50 \%$ that in ntg HDL when activity was normalized to total HDL protein (12.8 \pm 1.8 and $5.8 \pm 0.9 \mathrm{U}$ activity/mg HDL protein for nontransgenic and apoAII-transgenic mice, respectively; data are expressed as mean \pm SEM).

To examine the role of paraoxonase in the apparent lack of protection observed with HDL from the apoAII-transgenic mice, we repeated our coculture protection assays with HDL that had been supplemented with purified paraoxonase. As shown in Fig. 8, paraoxonase activity was increased significantly in apoAII-transgenic HDL that were reisolated after preincubation with purified paraoxonase, but paraoxonase supplementation did not significantly change the enzyme activity associated with the nontransgenic HDL. We then examined the ability of the paraoxonase-supplemented HDL to prevent LDL oxidation in coculture. apoAII-transgenic HDL that had been supplemented with paraoxonase showed a significant increase in protection and was now similar to HDL from the nontransgenic mice in the ability to prevent LDL oxidation (Fig. 9). There was no significant difference in the ability of nontransgenic HDL to protect against LDL oxidation after supplementation with paraoxonase (Fig. 9). We also examined the ability of the paraoxonase-supplemented HDL to stimulate lipid hydroperoxide production (Fig. 10). As observed previously, apoAII-transgenic HDL stimulated lipid hydroperoxide production even more than hLDL. However, after supplementation with paraoxonase, the stimulation by apoAII-transgenic HDL was markedly reduced (Fig. 10). Both sham-treated and paraoxonase-supplemented nontransgenic HDL had no stimulatory effect on lipid hydroperoxide production (Fig. 10).

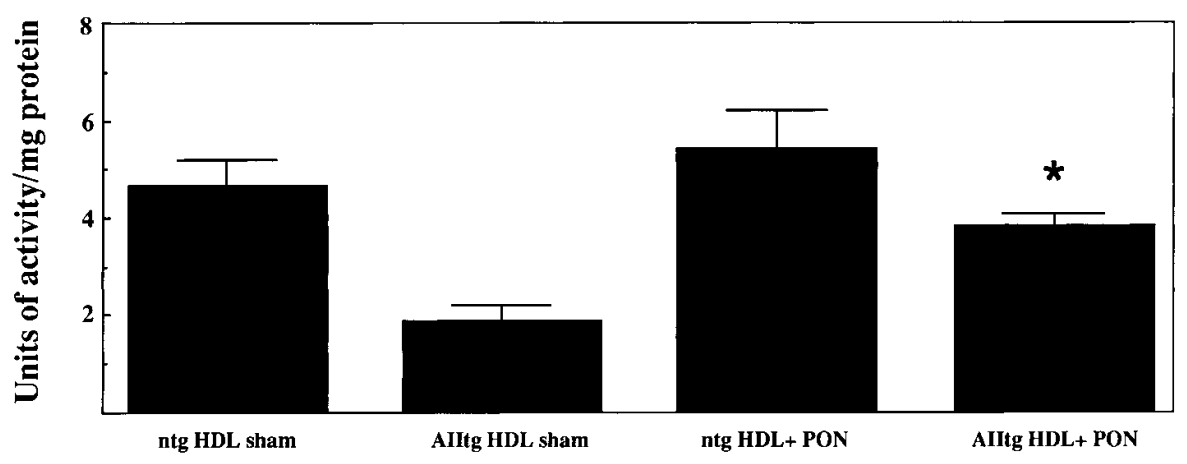

Figure 8. Paraoxonase activities in nontransgenic and apoAII-transgenic HDL after supplementation with paraoxonase. HDL from nontransgenic and apoAIItransgenic mice were incubated with purified human paraoxonase $(5 \mu \mathrm{g} / \mathrm{ml})$ for $4 \mathrm{~h}$ at $37^{\circ} \mathrm{C}$ with gentle shaking. After treatment, unbound PON was removed by filtering through a $100-\mathrm{kD}$ molecular weight filter. Sham-treated HDL went through the incubation and filtration without PON. Paraoxonase (14) activities were determined in sham-treated nontransgenic HDL (ntg HDL sham), sham-treated apoAII-

transgenic HDL (AIItg HDL sham), PON-supplemented nontransgenic HDL (ntg HDL + PON), and PON-supplemented apoAII-transgenic HDL (AIItg HDL $+P O N)$. The data are expressed as units of activity (nanomoles substrate hydrolyzed per minute) per milligram HDL protein using phenylacetate as substrate. All values are given as mean \pm SEM for four separate assays. The following symbols indicate significance $(P<$ 0.05 ) between the means of the various groups as calculated by $t$ test. *Significantly different than the corresponding sham-treated group. 


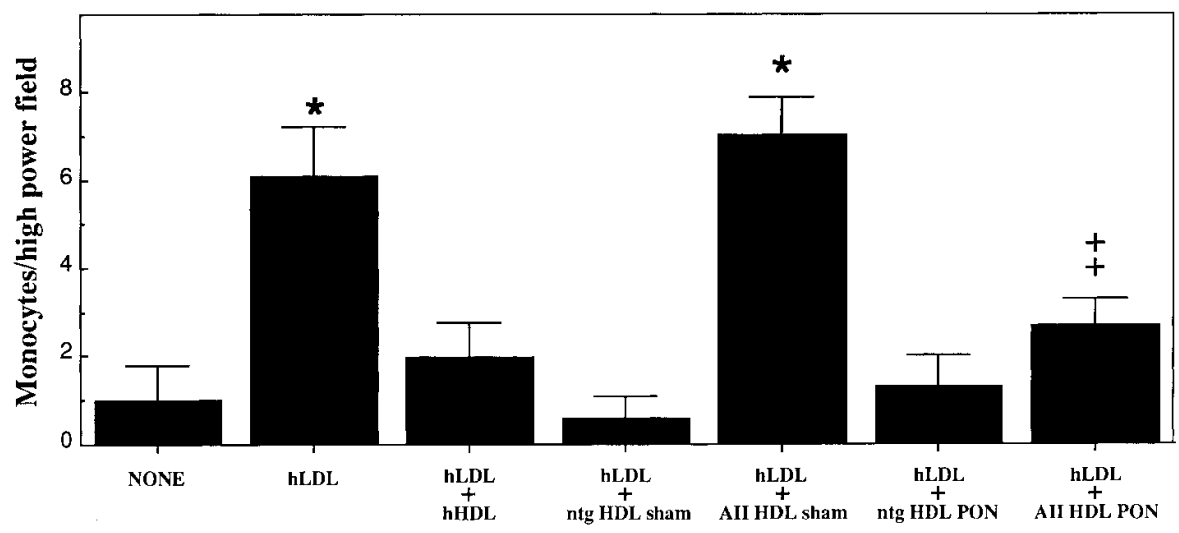

Figure 9. Effect of transgenic and nontransgenic HDL on LDL oxidation and monocyte transmigration in a coculture assay after supplementation with paraoxonase. The ability of HDL to protect LDL from oxidative modification was studied in cocultures of human aortic endothelial and smooth muscle cells. Human and mouse HDL $(d=1.063-1.21 \mathrm{~g} / \mathrm{ml})$ and human LDL $(d=1.019-1.063 \mathrm{~g} / \mathrm{ml})$ were isolated by sequential ultracentrifugation (10) and were used at $500 \mu \mathrm{g}$ HDL and $350 \mu \mathrm{g}$ LDL protein $/ \mathrm{ml}$ of medium. Cocultures of human aortic endothelial and smooth muscle cells were established as described previously (12, 22-24). HDL from nontrans-

genic and apoAII-transgenic mice were incubated with purified human PON $(5 \mu \mathrm{g} / \mathrm{ml})$ for $4 \mathrm{~h}$ at $37^{\circ} \mathrm{C}$ with gentle shaking. After treatment, unbound PON was removed by filtering through a $100-\mathrm{kD}$ molecular weight filter. Sham-treated HDL went through the incubation and filtration without PON. Coculture incubations were then carried out for $7 \mathrm{~h}$ with either no lipoproteins added $(N O N E)$, human LDL alone $(h L D L)$, human LDL and human HDL ( $h L D L+h H D L)$, human LDL and sham-treated nontransgenic HDL ( $h L D L+n t g H D L$ sham), human LDL and sham-treated apoAII-transgenic HDL $(h L D L+A I I H D L$ sham $)$, human LDL and PON-supplemented nontransgenic HDL $(h L D L+n t g$ $H D L P O N)$, and human LDL and PON-supplemented apoAII-transgenic HDL $(h L D L+A I I H D L P O N)$. After incubation for $7 \mathrm{~h}$, the culture media from four wells were pooled and loaded into individual wells in a standard neuroprobe chemotaxis chamber. A porous membrane was then placed over the wells and medium containing human monocytes was added to wells on the opposite side of the membrane. After $3 \mathrm{~h}$, the membranes were removed and the number of monocytes that had migrated through the membrane were counted. Monocyte transmigration is expressed as monocytes per high powered field. Values are given as mean \pm SEM for data from four chemotaxis wells. We have observed a complete agreement between the values for monocyte migration through the endothelial cells in the coculture and monocyte migration through the filters. All values are given as mean \pm SEM for four separate assays. The following symbols indicate significance $(P<0.05)$ between the means of

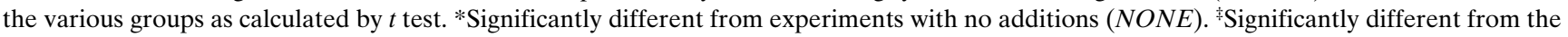
corresponding sham-treated group.

\section{Discussion}

Our studies have demonstrated a striking functional heterogeneity of HDL associated with differences in susceptibility to atherosclerosis. AItg mice appear to have increased resistance to atherosclerosis not only because HDL cholesterol levels are increased, but also because of enhanced ability of the HDL to promote cholesterol efflux. Overexpression of apoAII, on the other hand, had no effect on the ability of HDL to promote cholesterol efflux, but it dramatically altered the functional state of HDL, from antioxidant/antiinflammatory to prooxidant/proinflammatory, providing one possible explanation for the increased lesion development in the apoAII-transgenic mice. These results support the concept that the antioxidant properties of HDL are involved in protecting against atherosclerosis. They also provide the first evidence of an HDL particle that is potentially proatherogenic.

Previous studies have demonstrated that the apoAI/apoAII content of HDL can affect its ability to function in reverse cholesterol transport, one of the mechanisms through which HDL is believed to protect against the development of atherosclerosis. Some, but not all, studies found that HDL that contain only apoAI (termed LpA-I) were more effective than HDL that contain both apoAI and apoAII (termed LpA-I:A-II) in eliciting cholesterol efflux from cells in culture (31-36). Furthermore, cholesterol ester from LpA-I was shown to be more efficiently taken up by the liver and incorporated into bile acids in vivo than was cholesterol ester from LpA-I:A-II (31).

Based on these earlier studies, we anticipated that differences in lesion development between the apoAI- and apoAIItransgenic mice might reflect differences in their ability to function in reverse cholesterol transport. The results of our cholesterol efflux experiments suggest that the increased protection against atherosclerotic lesion formation in the apoAItransgenic mice may indeed be due to an increase in the ability to elicit cholesterol efflux from cells. On the other hand, our studies suggest that the increased lesion development observed in the apoAII-transgenic mice was not due to a diminished ability to function in reverse cholesterol transport, or at least in what is believed to be the first step in the process, the ability to promote cholesterol efflux from cells.

The finding that HDL from the apoAII transgenics and nontransgenics were not discernibly different in our cholesterol efflux studies prompted us to examine the ability of HDL to prevent LDL oxidation. There is accumulating evidence that HDL has antiinflammatory functions that may play a role in preventing atherosclerosis $(12,37-41)$. HDL has the ability to inhibit LDL oxidation in vitro and to protect against the effects of LDL oxidation in tissue culture. Based on the results of the present experiments, HDL from the apoAII-transgenic mice function differently than all other HDL examined and are unable to protect LDL against oxidation in the coculture model of the artery wall. We have repeated these experiments on many different occasions with HDL isolated from $\sim 300$ different mice and with aortic endothelial and smooth muscle cells from different human donors, and the results are consistent.

In the present study, not only was HDL from apoAII transgenics unable to prevent LDL oxidation, but, surprisingly, apoAII-transgenic HDL was actually proinflammatory. This was confirmed in two separate types of experiments that used different assays to measure oxidation: the transmigration of 


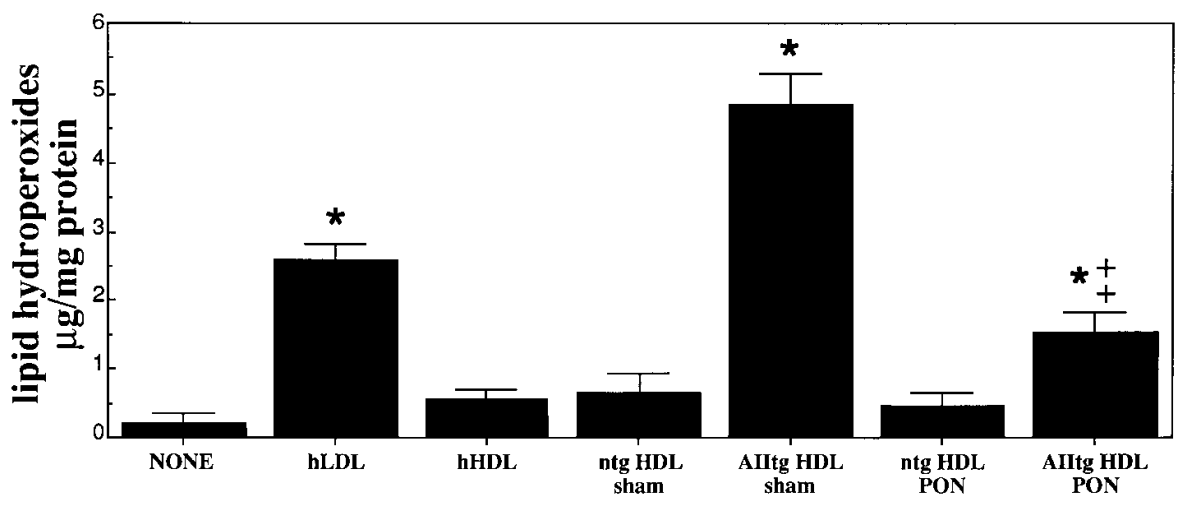

Figure 10. Effect of apoAII-transgenic and nontransgenic HDL on stimulating the oxidation of LDL by vascular cells after supplementation with paraoxonase. HDL from nontransgenic and apoAII-transgenic mice were incubated with purified human paraoxonase $(5 \mu \mathrm{g} / \mathrm{ml})$ for $4 \mathrm{~h}$ at $37^{\circ} \mathrm{C}$ with gentle shaking. After treatment, unbound PON was removed by filtering through a $100-\mathrm{kD}$ molecular weight filter. Sham-treated HDL went through the incubation and filtration without PON. Cocultures (as described in Fig. 4) were incubated with either no additions (NONE) or with $500 \mu \mathrm{g} / \mathrm{ml}$ of the following lipoprotein preparations: human LDL $(h L D L)$, human HDL $(h H D L)$, sham-treated nontransgenic HDL (ntg HDL sham), sham-treated apoAII-transgenic HDL (AIItg HDL sham), PON-supplemented nontransgenic HDL (ntg HDL PON), or PON-supplemented apoAII-transgenic HDL (AIItg $H D L P O N)$. After incubation for $24 \mathrm{~h}$, the medium and added lipoproteins were removed. After washing, the cells were incubated overnight with human LDL $(500 \mu \mathrm{g} / \mathrm{ml})$. The levels of lipid peroxides in the medium were then determined (16). The data are expressed as micrograms of linoleate hydroperoxide equivalent per milligram of LDL protein. Values are given as mean \pm SEM for results from three separate experiments. The following symbols indicate significance $(P<0.05)$ between the means of the various groups as calculated by $t$ test. *Significantly different than experiments without preincubation with lipoproteins $(N O N E)$. All values are given as mean \pm SEM for four separate assays. The following symbols indicate significance $(P<0.05)$ between the means of the various groups as calculated by $t$ test. *Significantly different from experiments without preincubation with lipoproteins $(N O N E)$. ${ }^{\ddagger}$ Significantly different from the corresponding sham-treated group.

monocytes in the coculture experiments and the production of lipid hydroperoxides during coculture. The validity of these independent measures of oxidation are strengthened by the fact that apoAII HDL that had not been incubated in coculture did not stimulate lipid hydroperoxide formation and, in separate experiments, also failed to stimulate monocyte transmigration. These data suggest that the apoAII-transgenic HDL did not contain chemotactic factors, but did contain oxidized lipids or other factors that promoted the production of monocyte chemotactic protein- 1 by the cells in culture. The stimulatory effect of apoAII-transgenic HDL does not appear to be due to contamination by LDL. We were unable to detect any appreciable amounts of apoB in our HDL preparations. Also, we compared stimulation of lipid hydroperoxide production by ultracentrifugally isolated LDL and HDL. HDL from the apoAII transgenics was much more potent (based on equal amounts of protein) than apoAII LDL in stimulating lipid hydroperoxide production (data not shown). Therefore, it is unlikely that a small amount of contaminating LDL in the HDL preparations was responsible for the stimulation in lipid hydroperoxide production.

Previous studies have revealed two enzymes carried on HDL, paraoxonase and PAF-AH, that are capable of inhibiting LDL oxidation by copper ions in vitro and in the coculture system (23-29), by destroying biologically active phospholipids in the oxidized LDL. We found no significant differences in PAF-AH activity in the HDL from the various strains of mice used in this study, but there was a $50 \%$ reduction in the activity of paraoxonase in the HDL from the apoAII-transgenic mice compared with HDL from nontransgenic littermates and other strains of mice. Total plasma paraoxonase activity was similar in both apoAII transgenics and nontransgenic controls, and all of the activity in both strains was found in the HDL fraction, as confirmed by gel filtration. The $50 \%$ reduction in paraoxonase per microgram of HDL protein in the apoAII transgenics compared with controls, is due to the fact that total plasma paraoxonase activity is similar between apoAII transgenics and controls, but HDL is markedly increased in the apoAII transgenics.

In our coculture system, oxidized lipids are produced by the cells as a normal consequence of aerobic metabolism. When LDL are then added to the incubations, oxidized lipids from the cells "seed" the LDL, initiating a chain reaction of lipid oxidation. This oxidized LDL induces the synthesis of monocyte chemotactic protein-1, which can then be recovered in the medium and its level assessed by the ability to induce monocyte adhesion and transmigration $(12,22)$. When HDL are added along with LDL, the HDL-associated enzymes, paraoxonase and PAF-AH, inactivate the oxidized lipids from the cells and prevent the "seeding" of the LDL. Not only can oxidized lipids produced by the cells stimulate oxidation of LDL, but the converse is also true; oxidized lipoproteins can stimulate lipid oxidation in the cells. When oxidized lipoproteins such as minimally modified LDL are added to the cell culture, incubated, and the cells washed, these cells now show a marked increase in oxidation of "normal" LDL upon subsequent incubation.

There appear to be two components to the increased oxidation observed with HDL from the apoAII-transgenic mice. First, the paraoxonase activity is reduced $50 \%$ in the apoAII transgenics compared with controls, based on equal amounts of total HDL protein. This reduction in paraoxonase most likely reduced the ability of the HDL to protect LDL from oxidation. Supporting this concept is the fact that supplementing the HDL with purified paraoxonase increased the paraoxonase activity of the reisolated HDL, as well as increasing protection. The second component is that the HDL from the apoAII-transgenic mice appear to contain an oxidized moiety that can stimulate lipid oxidation by cells in a similar manner to the stimulation observed when cells in coculture are preincubated with minimally modified LDL, as described above. The observation that lipid hydroperoxide levels on the HDL 
before incubation were similar between apoAII transgenics and nontransgenics raises the possibility that the stimulatory moiety on the HDL may not be an oxidized lipid, or at least one that we can measure with our assay. Paraoxonase also appears to play a role in the stimulatory effect of apoAII-transgenic HDL, since the apoAII-transgenic HDL that had been supplemented with purified paraoxonase exhibited a markedly diminished capacity to stimulate lipid hydroperoxide production. It has been reported that the majority of oxidized lipids present in the circulation occur in HDL. We believe that the oxidized lipids are picked up by a subfraction of HDL that usually contains paraoxonase, and the oxidized lipids are inactivated. It would appear that there is an increase in this subfraction in the apoAII-transgenic mice, but no increase in plasma paraoxonase, resulting in HDL particles that now accept the oxidized lipids but cannot inactivate them. The oxidized lipids on these HDL can then "seed" the cells in coculture, causing them to produce more oxidized lipids. Supplementing the apoAII-transgenic HDL with paraoxonase may have reduced lipid hydroperoxide production by the cells through inactivation of the stimulatory factor on the HDL. Alternatively, if the stimulatory factor is not a substrate for paraoxonase, the paraoxonase may have acted by destroying the lipid hydroperoxides produced by the cells in response to the stimulatory factor. These data indicate that HDLs influence cellular metabolism, which in turn affects lipid peroxidation of LDL, and they provide evidence of an HDL particle that may actually promote atherosclerotic lesion development.

Additional evidence supporting the fact that the decrease in paraoxonase on apoAII-transgenic HDL is responsible for both the lack of protection against LDL oxidation, as well as the stimulation of lipid hydroperoxide production by cells in culture, comes from recent ongoing experiments in our laboratory with paraoxonase knock-out mice. The HDL from the paraoxonase knock-out mice not only fail to protect against LDL oxidation in coculture, but also stimulate lipid hydroperoxide production by cells in culture to a similar degree as the apoAII-transgenic HDL (D. Shih and A. Lusis, personal communication). HDL from the paraoxonase knock-out and apoAII-transgenic mice are the only HDL we have observed that cause this stimulation.

We believe that the results of the experiments with HDL that were supplemented with paraoxonase in conjunction with the results from the paraoxonase knock-out mice provide strong evidence for the role of paraoxonase in both the lack of protection against LDL oxidation and the stimulation of lipid hydroperoxide production by cells in culture. However, the exact mechanism by which the HDL are stimulating lipid hydroperoxide production, and the part paraoxonase plays in this phenomenon, is unclear. The actual mechanism is probably more complex than what has been suggested above.

HDL from other strains of mice that have reduced paraoxonase activity also do not protect in the coculture experiments (as discussed below). However, only HDL from the paraoxonase knock-out and the apoAII-transgenic mice stimulate the production of oxidized lipids by cells in culture. This stimulatory effect of HDL from the apoAII-transgenic and paraoxonase knock-out mice may be due to different HDL subfractions in these strains. The efficacy of paraoxonase in attenuating the stimulatory effect may depend on its association with a certain HDL subfraction. This may explain why the paraoxonase sup- plementation experiments were not able to increase paraoxonase activity and the ability to prevent oxidation to the same levels as those observed in the nontransgenics. Alternatively, the inability to raise paraoxonase levels on the apoAII-transgenic HDL to levels observed in the nontransgenic HDL could be due to differences in binding affinity between murine and human paraoxonase. We are currently trying to determine what the HDL from the apoAII-transgenic and paraoxonase knock-out mice share in common.

While the proinflammatory nature of HDL from the AIItg mice may contribute to increased lesion formation, we cannot rule out the possibility that alterations in other lipoprotein fractions contribute to the accelerated lesion development in the apoAII-transgenic mice. It is noteworthy that, in the AIItg mice, other proteins, including apoE, were apparently displaced from HDL by apoAII (10). Furthermore, the VLDL and LDL lipoprotein fractions were altered in apoAII-transgenic mice (10), and LDL from the apoAII transgenics are more easily oxidized in coculture (data not shown).

Recently, C57BL/6J mice, which are susceptible to dietinduced atherosclerosis, have been shown to have a large decrease in both mRNA and plasma levels of paraoxonase when placed on an atherogenic diet, while $\mathrm{C} 3 \mathrm{H} / \mathrm{HeJ}$ mice, which are resistant to diet-induced atherosclerosis, exhibit no such decrease in paraoxonase in response to the atherogenic diet (42). When HDL were isolated from these animals and tested in the coculture monocyte transmigration assay, HDL from both strains were able to protect when the mice had been maintained on the chow diet, but on the atherogenic diet, only HDL from the resistant strain was able to protect. This suggests that the reduction in paraoxonase was important in stimulating lesion formation in the susceptible C57BL/6J mice. Furthermore, in a set of recombinant inbred strains derived from the susceptible and resistant strains, paraoxonase mRNA levels were found to cosegregate with aortic lesion area (42). Human epidemiologic and genetic studies are consistent with a role for paraoxonase in atherogenesis (43-46). Individuals with hyperlipidemia or insulin-dependent diabetes mellitus exhibited decreased paraoxonase activities as compared with control groups $(44,47)$. Several other studies have revealed significant correlations between serum paraoxonase activity and HDL-cholesterol, triglyceride, apoAI, LDL-cholesterol, and apolipoprotein B levels (48-50). In one retrospective study, patients with myocardial infarction exhibited significantly lower paraoxonase activity than the individuals in a control group (46).

These results with transgenic mice, demonstrating different functional states of HDL, provide an explanation for the observation that certain genetic syndromes associated with low levels of HDL are not strongly associated with differences in atherosclerosis susceptibility (8). These studies support the concept that specific subclasses of HDL can be more important than total HDL levels in protecting against the development of atherosclerosis. HDL are a heterogeneous group of lipoproteins with many diverse functions. It has long been suspected that only certain subfractions of HDL may be important in playing a role in protecting against atherosclerotic lesion development. Changes in the pool size and/or function of this "protective" subfraction is believed to be one factor contributing to increased atherosclerotic lesion development in some individuals. Our data raises the possibility that an- 
other factor in the etiology of atherosclerosis may be an as yet unidentified atherogenic HDL subfraction.

In conclusion, our studies provide strong support for the concept that HDL are functionally heterogeneous with respect to their ability to protect against LDL oxidation and atherogenesis. In fact, our results suggest that certain forms of HDL may be proinflammatory and proatherogenic. Such functional heterogeneity may explain, in part, why certain genetic disorders resulting in low HDL levels are not strongly associated with atherosclerosis (8).

\section{Acknowledgments}

We thank Drs. Jian-Hua Qiao, Dietrich Machleder, and Margarete Mehrabian, University of California, Los Angeles, for help with breeding the mice and lesion analysis of the apoAI-transgenic mice, and Dr. Jan Breslow for the apoAI-transgenic mice. We are also grateful to Drs. George Popjak, Karen Reue, and Mark Doolittle for critical review of the manuscript, and Dr. Diana Shih for providing information on the paraoxonase knock-out mice.

This work was supported by National Institutes of Health grants HL-30568 and HL-28481.

\section{References}

1. Miller, N.E. 1987. Associations of high density lipoprotein subclasses and apolipoproteins with ischemic heart disease and coronary atherosclerosis. Am. Heart J. 113:589-597.

2. Tall, A.R. 1990. Plasma high density lipoproteins. Metabolism and relationship to atherogenesis. J. Clin. Invest. 86:379-384.

3. Fielding, C.J., and P.E. Fielding. 1995. Molecular physiology of reverse cholesterol transport. J. Lipid Res. 36:211-228.

4. Parthasarathy, S.D., D. Steinberg, and J.L. Witztum. 1992. The role of oxidized low-density lipoproteins in the pathogenesis of atherosclerosis. Annu. Rev. Med. 43:219-225.

5. Berliner, J.A., M. Navab, A.M. Fogelman, J.S. Frank, L.L. Demer, P.A. Edwards, A.D. Watson, and A.J. Lusis. 1995. Atherosclerosis: basic mechanisms. Oxidation, inflammation, and genetics. Circulation. 91:2488-2496.

6. Parthasarathy, S., and N. Santanam. 1994. Mechanisms of oxidation, antioxidants, and atherosclerosis. Curr. Opin. Lipidol. 5:371-375.

7. Parthasarathy, S., J. Barnett, and L.G. Fong. 1990. High-density lipoprotein inhibits the oxidative modification of low-density lipoprotein. Biochim. Biophys. Acta. 1044:275-283.

8. Rader, D.J., K. Ikewaki, N. Duverger, I. Feuerstein, L. Zech, W. Connor, and H.B. Brewer, Jr. 1993. Very low high-density lipoproteins without coronary atherosclerosis. Lancet. 342:1455-1458.

9. Karathanasis, S.K. 1992. High density lipoprotein. In Molecular Genetics of Coronary Artery Disease. A.J. Lusis, J.I. Rotter, and R.S. Sparkes, editors. Karger, Basel, Switzerland. 140-171.

10. Warden, C.H., C.C. Hedrick, J.-H. Qiao, L.W. Castellani, and A.J. Lusis. 1993. Atherosclerosis in transgenic mice overexpressing apolipoprotein A-II. Science (Wash. DC). 261:469-472.

11. Walsh, A., Y. Ito, and J.L. Breslow. 1989. High levels of human apolipoprotein A-I in transgenic mice result in increased plasma levels of small high density lipoprotein (HDL) particles comparable to human HDL3. J. Biol. Chem. 264:6488-6494.

12. Navab, M., S.S. Imes, S.Y. Hama, G.P. Hough, L.A. Ross, R.W. Bork, A.J. Valente, J.A. Berliner, D.C. Drinkwater, H. Laks, and A.M. Fogelman. 1991. Monocyte transmigration induced by modification of low density lipoprotein in coculture of human aortic wall cells is due to induction of monocyte chemotactic protein 1 synthesis and is abolished by high density lipoprotein. $J$. Clin. Invest. 88:2039-2046.

13. Fogelman, A.M., F. Elahi, K. Sykes, B.J. Van Lenten, M.C. Territo, and J.A. Berliner. 1988. Modification of the Recalde method for the isolation of human monocytes. J. Lipid Res. 29:1243-1247.

14. Gan, K.N., A. Smolen, H.W. Eckerson, and B.N. LaDu. 1991. Purification of human serum paraoxonase/arylesterase. Evidence for one esterase catalyzing both activities. Drug Metab. Dispos. 19:100-106.

15. Stafforini, D.M., T.M. McIntyre, and S.M. Prescott. 1990. Platelet-activating factor acetylhydrolase from human plasma. Methods Enzymol. 187:344-357.

16. Auerbach, B.J., J.S. Keily, and J.A. Cornicelli. 1992. A spectrophotometric microtiter-based assay for the detection of hydroperoxy derivatives of linoleic acid. Anal. Biochem. 201:375-380.
17. Bernard, D.W., A. Rodriguez, G.H. Rothblat, and J.M. Glick. 1990. Influence of high density lipoprotein on esterified cholesterol stores in macrophages and hepatoma cells. Arteriosclerosis. 10:135-144.

18. Rubin, E.M., R.M. Krauss, E.A. Spangler, J.G. Verstuyft, and S.M. Clift. 1991. Inhibition of early atherogensis in transgenic mice by human apolipoprotein AI. Nature (Lond.). 353:265-267.

19. Qiao, J.-H., P.-Z. Xie, M.C. Fishbein, J. Kreuzer, T.A. Drake, L.L. Demer, and A.J. Lusis. 1994. Pathology of atheromatous lesions in inbred and genetically engineered mice. Arterioscler. Thromb. Vasc. Biol. 14:1480-1497.

20. Schultz, J.R., J.G. Verstuyft, E.L. Gong, A.V. Nichols, and E.M. Rubin. 1993. Protein composition determines the anti-atherogenic properties of HDL in transgenic mice. Nature (Lond.). 365:762-764.

21. Kawano, M., T. Miida, C.J. Fielding, and P.E. Fielding. 1993. Quantitation of pre beta-HDL-dependent and nonspecific components of the total efflux of cellular cholesterol and phospholipid. Biochemistry. 32:5025-5028.

22. Navab, M., G.P. Hough, L.W. Stevenson, D.C. Drinkwater, H. Laks, and A.M. Fogelman. 1988. Monocyte migration into the subendothelial space of a coculture of adult human aortic endothelial and smooth muscle cells. $J$. Clin. Invest. 82:1853-1863.

23. Watson, A.D., M. Navab, S.Y. Hama, A. Sevanian, S.M. Prescott, D.M. Stafforini, T.M. McIntyre, B.N. Du, A.M. Fogelman, and J.A. Berliner. 1995. Effect of platelet activating factor-acetylhydrolase on the formation and action of minimally oxidized low density lipoprotein. J. Clin. Invest. 95:774-782.

24. Watson, A.D., M. Navab, G.P. Hough, S.Y. Hama, B.N. La Du, L. Young, H. Laks, L.C. Permut, A.M. Fogelman, and J.A. Berliner. 1994. Biologically active phospholipids in MM-LDL are transferred to HDL and are hydrolyzed by HDL-associated esterases. Circulation. 90:I353.

25. Mackness, M.I., S. Arrol, and P.N. Durrington. 1991. Paraoxonase prevents accumulation of lipoperoxides in low-density lipoprotein. FEBS. Lett. 286:152-154.

26. Lorentz, K., B. Flatter, and E. Augustine. 1979. Arylesterase in serum: elaboration and clinical application of a fixed-incubation method. Clin. Chem. 25:1714-1720.

27. Stafforini, D.M., G.A. Zimmerman, T.M. McIntyre, and S.M. Prescott. 1992. The platelet-activating factor acetylhydrolase from human plasma prevents oxidative modification of low-density lipoprotein. Trans. Assoc. Am. Physicians. 106:44-63.

28. Mackness, M.I., S. Arrol, C. Abbott, and P.N. Durrington. 1993. Protection of low-density lipoprotein against oxidative modification by high-density lipoprotein associated paraoxonase. Atherosclerosis. 104:129-135.

29. Blatter, M.-C., R.W. James, S. Messmer, F. Barja, and D. Pometta. 1993. Identification of a distinct human high-density lipoprotein subspecies defined by a lipoprotein-associated protein, K-45. Identity of K-45 with paraoxonase. Eur. J. Biochem. 211:871-879.

30. Watson, A.D., J.A. Berliner, S.Y. Hama, B.N. La Du, K.F. Faull, A.M. Fogelman, and M. Navab. 1995. Protective effect of HDL associated paraoxonase-inhibition of the biological activity of minimally oxidized low density lipoprotein. J. Clin. Invest. 96:2882-2891.

31. Pieters, M.N., G.R. Castro, D. Schouten, P. Duchateau, J.C. Fruchart, and T.J. Van Berkel. 1993. Cholesterol esters selectively delivered in vivo by high-density-lipoprotein subclass LpA-I to rat liver are processed faster into bile acids than are LpA-I/A-II-derived cholesterol esters. Biochem. J. 292:819-823.

32. Ohta, T., R. Nakamura, Y. Ikeda, M. Shinohara, A. Miyazaki, S. Horiuchi, and I. Matsuda. 1992. Differential effect of subspecies of lipoprotein containing apolipoprotein A-I on cholesterol efflux from cholesterol-loaded macrophages: functional correlation with lecithin: cholesterol acyltransferase. Biochim. Biophys. Acta. 1165:119-128.

33. von Hodenburg, E., S. Hdinen, K.E. Howell, C. Luley, W. Kubler, and H.M. Bond. 1991. Cholesterol efflux from macrophages mediated by high-density lipoprotein subfractions, which differ principally in apolipoprotein A-I and apolipoprotein A-II ratios. Biochim. Biophys. Acta. 1086:173-184.

34. Oikawa, S., A.J. Mendez, J.F. Oram, E.L. Bierman, and M.C. Cheung. 1993. Effects of high-density lipoprotein particles containing apo A-I, with or without apo A-II, on intracellular cholesterol efflux. Biochim. Biophys. Acta. 1165:327-334

35. Johnson, W.J., E.P. Kilsdonk, A. van Tol, M.C. Phillips, and G.H. Rothblat. 1991. Cholesterol efflux from cells to immunopurified subfractions of human high density lipoprotein: LpA-I and LpA-I:A-II. J. Lipid Res. 32:19932000 .

36. Barbaras, R., P. Puchois, J.C. Fruchart, and G. Ailhaud. 1987. Cholesterol efflux from cultured adipose cells is mediated by LpAI particles but not by LpAI:AII particles. Biochem. Biophys. Res. Commun. 142:63-69.

37. Eggesbo, J.B., I. Hjermann, P.K. Lund, G.B. Joo, R. Ovstebo, and P. Kierulf. 1994. LPW-induced release of IL-8, TNF-alpha and sCD14 in whole blood and PBMC from persons with high or low levels of HDL-lipoprotein. Cytokine. 6:521-529.

38. Wurfel, M.M., S.T. Kunitake, H. Lichenstein, K.P. Kane, and S.D. Wright. 1994. Lipopolysaccharide (LPS) -binding protein is carried on lipoproteins and acts as a cofactor in the neutralization of LPS. J. Exp. Med. 180:10251035 .

39. Flegel, W.A., M.W. Baumstark, C. Weinstock, A. Berg, and H. 
Northoff. 1993. Prevention of endotoxin induced monokine release by human low- and high-density lipoproteins and by apolipoprotein A-I. Infect. Immun. 61:5140-5146.

40. Baumberger, C., D.R.J. Ulevitch, and J.M. Dayer. 1991. Modulation of endotoxic activity of lipopolysaccharide by high-density lipoprotein. Pathobiology. 59:378-383.

41. Vosbeck, K., P. Tobias, H. Muller, R.A. Allen, K.E. Arfors, R.J. Ulevitch, and L.A. Sklar. 1990. Priming of polymorphonuclear granulocytes by lipopolysaccharides and its complexes with lipopolysaccharide binding protein and high density lipoprotein. J. Leukocyte Biol. 47:97-104.

42. Shih, D.M., L. Gu, S. Hama, Y. Xia, M. Navab, A.M. Fogelman, and A.J. Lusis. 1996. Genetic-dietary regulation of serum paraoxonase expression and its role in atherogenesis in a mouse model. J. Clin. Invest. 97:1630-1639.

43. Mackness, M.I., D. Harty, D. Bhatnagar, P.H. Winocour, S. Arrol, M. Ishola, and P.N. Durrington. 1991. Serum paraoxonase activity in familial hypercholesterolaemia and insulin-dependent diabetes mellitus. Atherosclerosis. 86:193-199.

44. Pavkovic, E., V. Simeon, E. Reiner, M. Sucic, and V. Lipovac. 1993 Serum paraoxonase and cholinesterase activities in individuals with lipid and glucose metabolism disorders. Chem. Biol. Interact. 87:179-182.
45. Hegele, R.A., J.H. Brunt, and P.W. Connelly. 1995. Multiple genetic determinants of variation of plasma lipoproteins in Alberta Hutterites. Arterioscler. Thromb. Vasc. Biol. 15:861-871.

46. McElveen, J., M.I. Mackness, C.M. Colley, T. Peard, S. Warner, and C.H. Walker. 1986. Distribution of paraoxon hydrolytic activity in the serum of patients after myocardial infarction. Clin. Chem. 32:671-673.

47. Bowry, V.W., K.K. Stanley, and R. Stocker. 1993. High density lipoprotein is the major carrier of lipid hydroperoxides in human blood plasma from fasting donors. Proc. Natl. Acad. Sci. USA. 89:10316-10320.

48. Saha, N., A.C. Roy, S.H. Teo, J.S.H. Tay, and S.S. Ratnam. 1991. Influence of serum paraoxonase polymorphism on serum lipids and apolipoproteins Clin. Genet. 40:277-282.

49. Blatter Garin, M.C., C. Abbott, S. Messmer, M. Mackness, P. Durrington, D. Pometta, and R.W. James. 1994. Quantitation of human serum paraoxonase by enzyme-linked immunoassay: population differences in protein concentrations. Biochem. J. 304:549-554.

50. Hegele, R.A., J.H. Brunt, and P.W. Connelly. 1995. A polymorphism of the paraoxonase gene associated with variation in plasma lipoproteins in a genetic isolate. Arterioscler. Thromb. Vasc. Biol. 15:89-95. 